\title{
La estructura de oportunidades políticas para la acción de las ONG: El caso de Pro Búsqueda
}

\section{Introducción}

- María Ángeles Huete García

UNIVERSIDAD DE SALAMANCA

Entre las tendencias sociales y políticas más destacables en las sociedades contemporáneas, se encuentra la intensa discusión sobre la crisis y el futuro de la democracia en su forma representativa y, de forma más concreta, en lo referente al Estado de Bienestar.

Al hilo de esta discusión, desde hace algunos años, vienen produciéndose aportes teóricos referidos al papel que las ONG pudieran jugar tanto en lo referente a procesos democratizadores como en atención a la provisión de servicios. En este sentido, el papel que las ONG desempeñan aparece como un asunto de relevancia para las ciencias sociales, particularmente, la sociología y la ciencia politica. '

Este artículo trata el tema de la estructura de oportunidad política que las ONG utilizan en la conformación de políticas públicas. Para ello, se analiza el caso de la Asociación Pro Búsqueda de Niños Desaparecidos, de El Salvador. Se trata de identificar las oportunidades políticas surgidas en el sistema político salvadoreño y que han determinado o facilitado la decisión de Pro Búsqueda de plantear su demanda a la Asamblea Legislativa. Esta demanda consiste en la 
creación, mediante un decreto legislativo, de una Comisión Nacional de Búsqueda de niños desaparecidos durante el conflicto armado interno, en la que tengan cabida diversos sectores de la sociedad, tales como diputados de los diferentes partidos con representación en la Asamblea, miembros de las Fuerzas Armadas, representantes de la Procuraduría General de la República y de la Procuraduría para la Defensa de los Derechos Humanos, miembros de la Secretaría Nacional de la Familia, representantes del Instituto de Protección al Menor y miembros de diversas ONG.

El artículo señala tres elementos fundamentales que pueden ser considerados oportunidades políticas para la acción de Pro Búsqueda, y analiza cada uno de ellos. Dichos elementos son los siguientes:

- Inicio de un período de estabilidad de la democracia.

- Presión de los organismos internacionales para la implementación de los acuerdos de paz.

- Equilibrio de poderes en la Asamblea Legislativa.

Finalmente, en el apartado dedicado a las conclusiones, se ofrece una reflexión acerca de los resultados logrados por Pro Búsqueda en la Asamblea Legislativa hasta el momento, asi como algunas reflexiones sobre el futuro de estas reivindicaciones.

\section{Marco teórico}

La estructura de oportunidades politicas está constituida por los elementos del sistema político que intervienen en el proceso de acción de un determinado grupo social y que favorecen o limitan tanto su capacidad de movilización como la consecución de sus objetivos.'

Existen algunas definiciones muy esclarecedoras del concepto de oportunidad política. Eisinger definió por primera vez este concepto y entendió por oportunidad política el grado de posibilidades que los grupos tienen de acceder al poder e incidir en el sistema político. Por otra parte, Lipsky, aunque no habla de manera explícita de oportunidades políticas, sí se refiere a la actividad de protesta como un recurso político. En este sentido, liga las organizaciones de protesta con los procesos políticos generales en las cuales las organizaciones se desartollan.

Son Tilly, McAdam, Kitschelt y Katzenstein ${ }^{2}$ quienes formulan el término de oportunidad política de una manera más formal. Tilly no se refiere de la misma forma al concepto, aunque trabaja, sobre todo, con el término de oportunidad política, su idea al respecto se desarrolla en torno a las relaciones de poder. Asimismo, McAdam define la estructura de oportunidades politicas como 
el conjunto de relaciones de poder que define el contexto político. Dentro de la misma línea, Katzenstein entiende el concepto en términos de acceso a las instituciones del Estado, a la estabilidad de los alineamientos políticos y a la relación de los aliados y los grupos de apoyo.

Sidney Tarrow es el teórico que ha desarrollado de forma más profunda este concepto y lo ha definido de la siguiente forma: Al hablar de oportunidades politicas, me refiero a dimensiones congruentes (aunque no necesariamente formales o permanentes) del entorno politico que ofrecen incentivos para que la gente participe en acciones colectivas al afectar a sus expectativas de éxito o fracaso ${ }^{3}$.

En este sentido, Sydney Tarrow destaca cuatro dimensiones importantes en las que se enmarca la estructura de oportunidades politicas. Estas dimensiones son las siguientes:

- El grado de tendencia a la apertura del sistema político institucionalizado.

- La estabilidad en las alineaciones de las élites que defienden determinadas lineas politicas.

- La posibilidad de contar o no con el apoyo de las élites.

- La capacidad estatal para reprimir los movimientos sociales.

Para el análisis de las oportunidades politicas de Pro Búsqueda, tomaremos como marco teórico la perspectiva de Tarrow y trataremos de enmarcar las oportunidades políticas detectadas en las dimensiones descritas por el autor.

Por otra parte, existen dos formas de enfocar la teoría de oportunidades politicas: desde el plano estructural y desde el plano psicológico. Este artículo enfoca el análisis de la estructura de oportunidades politicas desde un plano estructural, es decir, nos centraremos en los elementos de un sistema político dado que explican el surgimiento y desarrollo de la acción colectiva. Este enfoque se centra, pues, en las situaciones políticas en las cuales los Estados se hacen vulnerables a la acción colectiva y en las cuales los grupos se movilizan para llevar a cabo su acción.

\section{El contexto político salvadoreño}

\subsection{Evolución política reciente}

Para hacer una breve descripción de la evolución política reciente de El Salvador, partiremos de finales de los años 70 , periodo en el que da comienzo la transición política. Es concretamente en 1979 cuando se inicia la transición politica que se cimienta sobre la base de una alianza entre sectores tradicionales de las Fuerzas Armadas y sectores de la Democracia Cristiana. Este modelo de

Lo estructura de oportunidades politicas para la acción de las ONG 
transición, al contrario que el nicaragüense, contó desde el principio con el visto bueno de los Estados Unidos.

El profesor Manuel Alcántara ${ }^{4}$ describe este proceso sobre la base de las siguientes características:

$\S$ Se impone una estrategia electoral técnicamente perfecta y que excluye otro tipo de complementos del término democracia a la mecánica electoral, sin considerar la situación medioambiental existente.

$\S$ Esta situación se encuentra en un conflicto civil armado por el que una de las partes implicadas queda excluida del juego electoral.

$\S$ Se adopta un calendario de reforma política clásico por el que se convocan primeramente elecciones para una Asamblea Constituyente y, una vez elaborada esta Constitución, se daría paso a la elección del Presidente.

$\S$ La implicación de Estados Unidos en el proceso se hace cada vez mayor. Esto se debe, por una parte, al cariz que toman los acontecimientos en Nicaragua $\mathrm{y}$, por otra, al relevo de la administración Carter por la de Reagan.

$\S$ Dada la composición del binomio que mantiene el poder, se imposibilita todo esclarecimiento y persecución, tanto de las violaciones de los derechos humanos cometidas por el régimen, como de las actuaciones de los paramilitares, entre las que se encuentra el asesinato de monseñor Romero y la matanza en sus funerales.

$\S$ Apenas se produce una reformulación del sistema de partidos, si bien es cierto que el grupo parafascista ORDEN pasó a constituir ARENA (Alianza Republicana Nacionalista), políticamente más articulado y con mayores posibilidades, y queda superada la tradicional marginación de los democristianos.

El devenir político de El Salvador, desde los ochenta hasta el comienzo de la década siguiente, se caracterizó por la puesta en marcha de un proceso electoral sin precedentes en su historia, continuado y regular, técnicamente perfecto, pero de carácter semicompetitivo. A su vez, este período se vio acompañado por un clima de guerra civil y exclusión política de la izquierda, cuyo máximo exponente era el Frente Farabundo Marti para la Liberación Nacional (FMLN).

En este clima de enfrentamiento, la derrota del gobiemo sandinista en Nicaragua, junto con el cambio de clima internacional, debilitó la posición de un FMLN que, por otra parte, nunca fue vencido y que en noviembre de 1989 había lanzado una seria ofensiva contra San Salvador, llegando a ocupar algunos barrios de la ciudad. Por otra parte, la nueva situación a la que no era ajena la consolidación de ARENA como fuerza política dominante, llevó a la apertura de la negociación entre representantes del gobierno y del FMLN en Ginebra en 
abril de 1990. En ese momento, se ponia en marcha el proceso de paz que llevaria al final del enfrentamiento bélico.

Este camino hacia la paz culminaría en las elecciones de 1994, en las que coincidían los comicios presidenciales, legislativos y municipales, y en las que debía concurrir con plenas garantías la izquierda salvadoreña. Estas elecciones se saldaron con la amplia ventaja de ARENA frente al resto de fuerzas políticas.

Las siguientes elecciones legislativas —celebradas en 1997- supusieron un duro revés para el gobierno, al perder ARENA la cómoda mayoría de la que disponia en la Asamblea y quedar su grupo parlamentario con un solo diputado más que el FMLN. Por otra parte, éste último incrementaba notablemente su poder municipal haciéndose con el control de San Salvador.

Las elecciones presidenciales del 7 de marzo de 1999 supusieron el triunfo del candidato de ARENA, Francisco Flores, quien derrotó por un amplio margen a Facundo Guardado, que lideraba la coalición electoral "Por el cambio", integrada por el FMLN y la Unión Social Cristiana (USC). Sin embargo, el cambio más significativo se produjo en las elecciones del año 2000 a la Asamblea, donde el FMLN se situó como partido mayoritario con dos diputados más respecto a ARENA.

\section{La sociedad civil salvadoreña}

\subsection{Los actores políticos y sociales}

Después del conflicto interno, la sociedad civil salvadoreña se encontraba en un aparente estado de letargo, mostrando una conducta próxima a la indiferencia y a la apatía. Esta situación se debía a dos factores fundamentales. Por una parte, la sociedad había estado, durante generaciones, bajo el poder del autoritarismo que impedía la movilización social. Dentro de esta cultura autoritaria, el terror fue un elemento de fuerza para coartar, cohibir o castigar al ciudadano por sus demandas uy manifestaciones pacíficas. No existía, por tanto, una cultura de movilización fuera de la desempeñada durante el conflicto armado.

Por otra parte, una vez finalizado el conflicto, muchos de los lideres que dirigieron el movimiento social durante la guerra, pasaron a la esfera política, convirtiéndose ahora en líderes de los nuevos partidos políticos legalizados. De esta forma, el movimiento social quedó huérfano, sin referentes claros.

En la actualidad, comienzan a emerger nuevos líderes y organizaciones que retoman las demandas sociales. Han tomado, o siguen teniendo, un peso especial los siguientes actores:

En el ámbito sindical, se ha gestado la creación de la Unidad Nacional de los Trabajadores Salvadoreños (UNTS). Los sindicatos más combativos se encuentran en el sector público. Entre ellos figuran el Sindicato de Trabajadores del 
Instituto Salvadoreño del Seguro Social (STISS), la Asociación Nacional de Educadores Salvadoreños (ANDES 21 de Junio), la Asociación Nacional de Trabajadores del Ministerio de Salud Pública y Asistencia Social (ANTMSPAS), la Asociación de Empleados del Ministerio de Hacienda (AGEMHA), la Asociación de Productores Agrícolas Salvadoreños (APROAS), la Asociación de Magistrados y Jueces de El Salvador (AMJUS) y la Asociación de Jueces de Paz de El Salvador (AJUPES).

Las organizaciones del sector privado empresarial conforman un frente muy activo y numeroso que, desde la década de los años setenta, viene desempeñando un papel destacado en el proceso de modernización tutelada de la economía del país. Vinculadas tradicionalmente a la derecha política, han influido en su proceso de reconversión. Entre ellas destaca la Alianza Productiva, uno de cuyos socios más activos es la Asociación Nacional de la Empresa Privada (ANEP), que reúne a un importante número de entidades, asociaciones y cámaras. La ANEP desempeñó un papel decisivo a la hora de la puesta en marcha de ARENA. Por otro lado, se encuentra la Unión Productiva Salvadoreña, la Asociación Salvadoreña de Industriales (ASI), la Asociación Bancaria Salvadoreña (ABANSA), la Cámara de Comercio e Industria de El Salvador (CCIES) y la Cámara Salvadoreña de la Construcción (CASALCO). Otras asociaciones gremiales más pequeñas, pero más combativas, son la Asociación de Empresarios de Autobuses Salvadoreños (AEAS), la Federación Nacional de la Pequeña Empresa (FENAPES) y la Asociación de Medianos Empresarios de El Salvador.

Por otra parte, la Iglesia Católica ha jugado un papel destacado a la hora de denunciar las contradicciones sobre las que se estaba basando el nuevo régimen, las cuales comportaban exclusividad y violaciones impunes de los derechos humanos. Igualmente, la elaboración de salidas del conflicto, que asegurasen la paz por mediación del diálogo y la negociación ha sido una pauta permanente.

Puede decirse que la Iglesia católica ha sido y es un actor de peso dentro de la sociedad civil salvadoreña. Actualmente los salvadoreños suelen vincularse más a organizaciones religiosas de cualquier indole que a otro tipo de organismo social. Prueba de ello es que más del $60 \%$ de la población se declara vinculada a alguna organización religiosa. Aun así, la tendencia de la participación ciudadana en algunas organizaciones ha aumentado, leve pero constantemente, desde $1995^{5}$.

Es importante destacar a las Organizaciones No Gubernamentales, tanto locales como internacionales, que han supuesto un empuje a la sociedad civil salvadoreña y que han contribuido a la realización de actividades de desarrollo, aumentando de forma paulatina su capacidad para movilizar recursos, para facilitar alianzas entre trabajadores e intelectuales, o para, como es el caso que nos ocupa, presionar en foros nacionales e internacionales. 
Óscar Martinez Peñate hace la siguiente reflexión al respecto:

Las ONG desempeñan un papel estratégico en la reconstrucción nacional y la construcción de la democracia en El Salvador, por lo que disputarse entre los partidos políticos las direcciones de las mismas constituye un error ya que se coarta la participación y manifestación de la sociedad civil. Al convertirlas en organismos partidarios, automáticamente entran en la esfera de la sociedad política. Ello no excluye que los partidos politicos tengan sus propias $O N G$ con fines electorales y partidarios $^{6}$.

\subsection{Las ONG como actores del proceso político}

La participación de las ONG en el proceso político no siempre ha sido bien recibida. Esta aceptación ha variado en función de las condiciones sociales y económicas en las que han desarrollado su acción. En este sentido, las ONG han sido vistas como periféricas de un sistema fuerte de gobierno, como esenciales y deseables como actores en la distribución pluralista del poder, como una amenaza para la democracia o como la legitimación de la futura democracia. Su participación, por tanto, se ha visto tradicionalmente a través de canales institucionalizados de cooperación, o a través de tácticas de confrontación con el único objetivo de presionar a las administraciones públicas.

En los últimos años, las ONG han experimentado un gran crecimiento en su actividad e influencia y han protagonizado importantes cambios que han redefinido su papel social. Especialmente en las dos últimas décadas, este avance se ha producido dentro de las sociedades democráticas y han creado tanto relaciones cooperativas como competitivas con el gobiemo para el desarrollo de políticas públicas y distribución de servicios. Podemos afirmar que las ONG compiten en cierta forma con el Estado, al representar éstas una alternativa para la satisfacción de las demandas de los ciudadanos. Pero esta competencia puede ser leal o desleal. Leal, porque puede animar a la administración a ser más cooperativa, y desleal, porque ofrece una alternativa al Estado con democracia aparente, apertura, eficacia y sensibilidad. Mediante este ofrecimiento, puede legitimarse la debilidad del Estado.

Raúl Leis, político e intelectual centroamericano, manifiesta lo siguiente:

Los tiempos que estamos viviendo han generado diversos cambios, y uno de ellos es la capacidad de los sectores de la sociedad civil, llámense ONG, llámense determinados movimientos sociales, para relacionarse con el Estado, planteando, incluso, agendas públicas, y muchas veces, sin ni siquiera contar con los partidos.'

Desde la perspectiva política y económica, se ha ofrecido una explicación al auge de las ONG, enmarcándolo en el contexto de la crisis del Estado de Bienestar y la aparente crisis de confianza en las instituciones democráticas. 
Algunos autores como Joan Subirats ${ }^{8}$ han identificado un número de características sociopolíticas que han conducido al desarrollo de las ONG:

$\S$ Aumento de la diversidad política, étnica, religiosa y compleja de los servicios públicos y aumento de las demandas relacionadas con cambios sociales.

$\S$ Falta de confianza en la burocracia y en las políticas tradicionales relacionadas con el aumento de la percepción de la corrupción.

$\S$ Creación de un servicio alternativo que pueda eludir la rigidez de los procedimientos gubernamentales y ser más consciente de las necesidades.

$\S$ Aumento de la capacidad organizativa de los ciudadanos.

$\S$ Incremento de los mecanismos para prestar servicios y aumento de la preocupación acerca de la calidad de los servicios contra la cantidad.

$\S$ Disminución del Estado de Bienestar, lo cual requiere estructuras que pueden ser más eficientes económicamente que las agencias públicas y mantener los servicios a pesar de los recortes presupuestarios.

\subsection{El papel de las ONG en la sociedad civil salvadoreña}

En El Salvador se van creando nexos importantes entre las organizaciones no gubernamentales y el proceso de definición de políticas. En esta dirección, se orienta la acción de las primeras, las cuales inciden en la esfera pública con un impacto significativo en lo que respecta a la comunicación de sus mensajes. Sin embargo, cabe señalar que la mayoria de las herramientas que hoy están usando las organizaciones para influir en la esfera política son exactamente iguales a las que esas mismas ONG, los movimientos sociales, las comunidades eclesiales de base y otros grupos de similares características utilizaban hace dos décadas. La diferencia radica en el énfasis que hoy se coloca en las propuestas y en la perspectiva más a largo plazo que anima a la formulación de una política pública.

Los patrones de cambio que estas asociaciones han puesto en juego en los distintos momentos de su existencia han servido en ocasiones como prefiguración de conductas o procedimientos adoptados posteriormente en otros niveles del Estado o de la sociedad. Este hecho se corresponde con la idea de McCarthy y Zald, quienes equipararon los movimientos sociales con el motor de cambio de la sociedad por las organizaciones que generan.

En El Salvador, las ONG florecieron durante el conflicto bélico, como resultado de las aspiraciones de paz, democratización y desarrollo de la sociedad civil. Fueron instituciones que canalizaron las demandas e iniciativas de la sociedad civil, y captaron la cooperación y solidaridad internacionales, destinadas a favorecer a la población más afectada por la guerra. La sociedad civil, por su parte, se fortaleció con la presencia de las ONG para presionar con mayor ener- 
gía por la salida negociada de la guerra, razón por la cual el gobierno y los militares consideraron a las ONG como organismos de fachada del FMLN.

Un factor que, entre otros, ayudó a ganar credibilidad a las ONG, fue que las instituciones gubernamentales sufrian un gran desprestigio, tanto a nivel nacional como internacional, por la corrupción que prevalecía a nivel institucional, el excesivo burocratismo y la incapacidad notoria para dar respuestas a determinadas demandas de la sociedad civil.

En la actualidad, las ONG desempeñan un papel más significativo como parte de la población civil que como instituciones de la sociedad política. Esto no implica que los partidos políticos no puedan tener -y, de hecho, las tienen- sus propias ONG.

Estas instituciones todavía continúan brindando un aporte, no sólo para reconstruir el país en los aspectos del desarrollo político, económico y social, sino que también desarrollan una labor importante, encaminada a tratar de construir la democracia en el pais.

Estas ONG, por lo general, las dirigen profesionales provenientes de diferentes estratos sociales, académicos y políticos, y el punto de convergencia de la mayoría de ellas es la construcción de la democracia, crecimiento y desarrollo de El Salvador.

Con las actividades que realizan las ONG, se involucran sectores de la población civil y fortalecen su desarrollo mediante la participación de ésta. Así, entre todos, identifican los principales problemas y necesidades prioritarias locales y nacionales. Asimismo, tratan de encontrar y proponer soluciones.

En este mismo esfuerzo, la Organización de Naciones Unidas para la Ciencia y la Cultura (UNESCO) está trabajando con 190 ONG para la ejecución de varios proyectos, con el objeto de rescatar los valores ancestrales de la paz y, en cierta medida, la identidad nacional, para ir ampliando el espacio en que germine la paz y la democracia. El programa impulsado por la UNESCO se llama Cultura de Paz en El Salvador.

Por otra parte, el Plan de Reconstrucción Nacional de El Salvador, en las fases de ejecución y programas, se ha esforzado en el fortalecimiento democrático. En la ejecución de este Plan, las ONG han tenido una participación destacada, pues 174 de ellas han trabajado junto con cinco organismos internacionales; 115 , con gobiernos locales y diecisiete, con organismos gubernamentales. En otras palabras, se han reunido un total de 311 ejecutores. ${ }^{9}$

Es necesario, además, referirse, aunque sea brevemente, a las asociaciones de derechos humanos. El movimiento de derechos humanos ha estado conformado mayoritariamente por organizaciones no gubernamentales. En América 
Latina y, por supuesto, en El Salvador, ha sido uno de los distintivos de la nueva oleada democratizante que terminó con los regímenes autoritarios.

Si bien las organizaciones de derechos humanos han disminuido su presencia e impacto público después de recuperada la democracia, este movimiento ha generado una inflexión cultural que ha alterado patrones muy establecidos en la cultura política. En este sentido, ha renovado la tradición democrática uniendo dos vertientes: la democrática y la constitucional. Así, no sólo ha deslegitimado al autoritarismo militar, sino que ha dotado de legitimidad a una forma constitucional de democracia, absolutamente deteriorada y desprestigiada al momento de iniciarse el período de violencia.

\section{El caso de la ONG Pro Búsqueda}

\subsection{Razón de ser y objetivos de Pro Búsqueda}

Pro Búsqueda es una organización sin ánimo de lucro, destinada a la defensa de los derechos humanos. Está formada por familiares de niños desaparecidos durante el conflicto armado, jóvenes que posteriormente fueron encontrados y personas afectadas de forma más indirecta por la desaparición de niños. Todos ellos realizan la búsqueda de niños desaparecidos en la guerra y promueven su integración familiar y social, reivindicando sus derechos de identidad, filiación y promoviendo su reparación moral y material.

Esta asociación surgió en agosto de 1994, a raiz de una iniciativa de familiares de niños desaparecidos y defensores de los derechos humanos. En la actualidad, Pro Búsqueda es una asociación formalmente constituida, con personalidad jurídica, que representa a más de $\mathbf{4 5 0}$ familias afectadas por la desaparición de niños.

De forma concreta, esta asociación plantea los siguientes objetivos ${ }^{10}$ :

$\S$ Promover la búsqueda y establecer el paradero de los niños desaparecidos

$\S$ Defender el derecho a la identidad de los niños desaparecidos

$\S$ Promover y acompañar el proceso de reintegración entre los niños encontrados y su familia de origen

$\S$ Reivindicar el derecho a la reparación moral y material de los familiares de los niños desaparecidos y los niños (ahora ya jóvenes) encontrados

$\S$ Contribuir a la recuperación de la memoria histórica

$\S$ Apoyar iniciativas que tiendan a asegurar la prevención, sanción y erradicación de violaciones de los derechos de la niñez

$\S$ Promover la participación de instituciones gubernamentales y no gubernamentales en la resolución de la problemática de los niños desaparecidos 
Para el logro de estos objetivos, Pro Búsqueda plantea a la Asamblea Legislativa la creación de una Comisión Nacional de Búsqueda. Esta demanda se analiza de forma más exhaustiva en el siguiente apartado.

\subsection{La demanda de Pro Búsqueda}

El 13 de octubre de 1999, Pro Búsqueda presentó a la Asamblea Legislativa el anteproyecto de ley para la creación de una Comisión Nacional de Búsqueda. En dicho anteproyecto, se entiende por niño desaparecido a todo salvadoreño que, en el momento de su desaparición en el marco del conflicto armado interno, tuviera menos de dieciocho años de edad. (Art. 1)

El anteproyecto propone la creación de la denominada Comisión Nacional de Búsqueda de Niños Desaparecidos Como Consecuencia Del Conflicto Armado Interno, como entidad de Derecho Público, con autonomia en lo técnico, financiero y administrativo.

La Comisión tendrá como misión investigar y determinar el paradero y situación de los niños desaparecidos como consecuencia del conflicto armado interno en El Salvador y propiciar el reencuentro con su familia de origen.

Para el efectivo cumplimiento de su objetivo, la Comisión promoverá la participación de la comunidad y las instituciones públicas y privadas.

La Comisión desarrollará sus actividades en un plazo máximo de dos años, a partir de la fecha de vigencia del Decreto.

Son fines de la Comisión los siguientes $1 "$ :

- Promover la integración entre las personas que anteriormente fueron niños desaparecidos, su familia de origen y su familia adoptivo y/o sustituta, teniendo en cuenta el interés superior de la niña o niño.

- Facilitar, cuando sea necesario y conveniente, las relaciones armónicas entre la familia de origen de los niños desaparecidos y su familia adoptiva y sustituta.

- Brindar asistencia profesional a los niños desaparecidos y a su familia.

- Promover la participación activa de entidades públicas y organizaciones de la sociedad civil para desarrollar acciones que contribuyan a la búsqueda de los niños desaparecidos.

- Preservar el derecho a la identidad, incluido la nacionalidad, el nombre y relaciones familiares de los niños desaparecidos.

- Contribuir a la reconciliación nacional y al fortalecimiento del estado democrático de derecho. 


\subsection{La estructura de oportunidades políticas para la acción de Pro Búsque- da}

Partiendo de la teoria de oportunidades políticas formulada por Sidney Tarrow, existen una serie de dimensiones en las que se enmarcan las oportunidades políticas. Dichas dimensiones son las siguientes:

1. El grado de tendencia a la apertura del sistema político institucionalizado

2. La estabilidad en las alineaciones de las élites que defienden determinadas lineas políticas

3. La posibilidad de contar o no con el apoyo de las élites y/o aliados.

4. La capacidad estatal para reprimir los movimientos sociales.

Dentro de algunas de estas dimensiones se insertan las oportunidades políticas identificadas como determinantes para la acción de Pro Búsqueda. Concretamente, las oportunidades politicas de Pro Búsqueda se encuentran en la dimensión de Tarrow referida a la apertura del sistema político y la referida a la estabilidad en las alineaciones de las élites.

Por otra parte, me gustaría añadir una nueva dimensión, aparte de las propuestas por Tarrow, la cual denomino presión de fuerzas externas. En esta dimensión se enmarca la tercera oportunidad que considero determinante para la acción de Pro Búsqueda.

A continuación se presentan las oportunidades politicas detectadas:

\section{- Inicio de un período de estabilidad para la democracia}

Esta oportunidad se encuentra enmarcada en la dimensión definida por Tarrow y relacionada con la tendencia a la apertura del sistema político.

En El Salvador, el proceso de transición a la democracia se inauguró con la firma de los Acuerdos de Paz de 1992. Ese proceso se caracterizó por el impulso y la ejecución de profundas transformaciones institucionales, orientadas a la creación de los espacios y condiciones necesarias para la instauración y la consolidación de la democracia.

Esta reforma iniciada con los Acuerdos de Paz constituyó un momento fundamental para la democracia salvadoreña. La década de los 90 fue para El Salvador, por tanto, un período de transición del régimen político, entendiendo por tal concepto los patrones que determinan las formas y los canales de acceso al poder, los márgenes de acción de los titulares de éste y las características de los actores que son admitidos y excluidos para acceder al mismo. En definitiva, lo que estuvo en juego durante la etapa negociadora previa a la transición fue la transformación, no del depositario del poder, sino de los mecanismos, formas de acceso y ejercicio del poder. 
Las transformaciones que se llevaron a cabo $^{12}$ han conducido a que El Salvador haya alcanzado unos logros gracias a los cuales podemos hablar de una cierta consolidación de la democracia. Entre ellos, son especialmente destacables los siguientes:

\section{- Competencia partidista en las elecciones legislativas}

Desde 1994 hasta 2000 se han celebrado tres eventos para elegir diputados de la Asamblea Legislativa en el país. El partido más votado en todos ellos ha sido ARENA, pero su margen de victoria se ha ido reduciendo. Este comportamiento manifiesta una mayor competitividad $y$, por tanto, una incertidumbre cada vez mayor sobre los resultados electorales.

Por otra parte, con las elecciones de 2000 , el proceso parece mostrar con mayor claridad una tendencia orientada a la relativa estabilización de la fuerza de los partidos mayoritarios. En otras palabras, a un sistema polarizado con independencia del pluralismo de quienes compiten.

Con todo, los avances en materia de libertad y competitividad en el sistema han sido notables, y los resultados muestran un asentamiento cada vez mayor del estado de derecho y el respeto al principio de alternabilidad.

El hecho de que exista una posibilidad real de alternancia en el poder, hace que las demandas de los ciudadanos tengan mayor calado en las agendas políticas, al depender cada vez más los partidos de los votos de los ciudadanos para lograr vencer en los comicios. En este contexto, la posibilidad de que Pro Búsqueda pueda canalizar sus demandas y lograr los resultados deseados en la Asamblea Legislativa aumentará en la medida en que la posibilidad real de alternancia a la que me he referido se consolide a lo largo del tiempo.

\section{- Cultura política y capital social}

Como ya se ha mencionado, los Acuerdos de Paz condujeron a profundas transformaciones institucionales orientadas a la creación de los espacios para la instauración y consolidación de un régimen democrático. Sin embargo, los acuerdos formales y acciones institucionales no emprendidas, no incorporaron de manera sustantiva la búsqueda y construcción de una cultura política a favor de las instituciones que se crearon a raiz de la democracia. En este caso en concreto, nos referimos a los partidos políticos.

En El Salvador, las instituciones de carácter más politico mantienen los indices más bajos de credibilidad popular, lo cual afecta su legitimidad pública y su relación política con la ciudadanía.

Los datos disponibles a finales de $1999^{13}$, muestran que la población salvadoreña confia mucho menos en los partidos políticos que en cualquier otra insti-

La estructura de oportunidades políticas para la acción de las ONG 
tución. En este sentido, menos del $5 \%$ de la ciudadanía expresó completa confianza en los partidos políticos, y más del $50 \%$ mostró una incredulidad total hacia este tipo de instituciones. ${ }^{14}$

Con respecto a la confianza en los procesos electorales, el sistema electoral enfrenta desde algunos años el problema de la abstención de la mayoria de la población. En los últimos cuatro procesos electorales, no sólo ha disminuido el nivel de participación ciudadana, sino también, y de forma más constante, la confianza de la ciudadanía en tales procesos. Los datos indican que en el año 2000 menos gente confiaba plenamente en los procesos electorales que en 1994.

Este hecho es visto como una oportunidad política para Pro Búsqueda, ya que la confianza de la sociedad civil en que organizaciones como ésta puedan canalizar sus demandas directamente ante la Asamblea Legislativa aumenta a medida que disminuye la confianza en los partidos políticos como canalizadores de sus reivindicaciones. Se pone de manifiesto en El Salvador, por tanto, la existencia de un nuevo modelo de democracia (democracia asociativa), en la que tendrían mayor cabida actores como Pro Búsqueda, como canalizadores de las demandas de los ciudadanos.

Por el contrario, frente a la escasa credibilidad de la que gozan los partidos políticos, la ciudadanía piensa que el sistema político de hace diez años era mejor que el sistema resultante de la posguerra, pero sigue confiada con respecto al futuro del país. Un poco más de la mitad de la población (54\%) sigue sosteniendo que la democracia es el mejor sistema politico bajo cualquier circunstancia. Sólo un $12.3 \%$ reivindica un gobierno autoritario, mientras que a un $21.2 \%$ le da igual la presencia de una democracia o un gobierno autoritario.

Esta situación nos lleva a la conclusión de que, a pesar de las actuales reticencias, los salvadoreños confian en la democracia como sistema politico futuro $\mathrm{y}$, por tanto, plantear sus demandas a la administración pública - en este caso, a la Asamblea Legislativa-, seria la forma de proceder que los salvadoreños considerarian más adecuada.

\section{— Equilibrio de poderes en la Asamblea Legislativa}

Esta oportunidad se enmarca en la dimensión que Tarrow denomina "estabilidad en las alineaciones de las élites que defienden determinadas líneas políticas".

Tras el fin de la guerra, la politica salvadoreña se ha caracterizado por la paulatina incorporación de la izquierda al sistema político. Dificilmente, alguno de los comicios celebrados entre 1982 y 1994 puede considerarse como elecciones fundacionales de un nuevo régimen, que marcasen la instauración de la democracia. Más bien, fueron elecciones demostrativas, como señala Manuel 
Alcántara, quien, además, afirma que el electoralismo fue engranaje de una política más general con imbricaciones internas y externas y que, negativamente, impidió por sí mismo fórmulas consensuales entre los principales actores en liza. ${ }^{15}$

Las elecciones, desde 1982, se caracterizaron por la presencia de la derecha encarnada, entre 1982 y 1985, por el PCN (Partido de Conciliación Nacional), tomando ARENA el relevo a partir de 1988 y manteniéndose en mayoria hasta 1997, año en el que el margen con el FMLN empezó a estrecharse. Realmente, las elecciones de 1997 supusieron un serio revés para ARENA, entonces en el poder, al perder la cómoda mayoría de la que disponía en la Asamblea Legislativa y quedar su grupo parlamentario con un solo diputado más que el FMLN. Por otra parte, éste último incrementaba su poder municipal haciéndose con el control de San Salvador.

Finalmente, las elecciones legislativas de 2000 consolidaron la tendencia de crecimiento del FMLN en la Asamblea Legislativa, llegando a tener un total de 31 diputados, frente a los 29 de ARENA.

La presencia mayoritaria del FMLN en la Asamblea es considerada una oportunidad política en la acción de Pro Búsqueda. Este hecho se da, no tanto por la existencia de una alternancia real en el poder, de la que ya hemos hablado, sino por el interés de muchos de los miembros del FMLN tienen en que se cree la Comisión Nacional de Búsqueda, al estar ellos mismos directamente afectados por el problema de la desaparición de niños. De hecho, Pro Búsqueda ha contado con el apoyo de esta fuerza política durante todo el proceso de creación de la citada Comisión. Esta fracción constituye, pues, un apoyo sólido para las demandas de Pro Búsqueda en la Asamblea Legislativa.

- Presión de los organismos internacionales para la implantación de los acuerdos de paz en temas relacionados con los derechos humanos

Esta oportunidad está enmarcada en la nueva dimensión propuesta que he denominado presiones externas.

El proceso de paz iniciado en El Salvador, con la firma de los Acuerdos de Paz, el 16 de enero de 1992, brindó la oportunidad de construir las bases sobre las que erigir el sistema democrático.

Después de más de veintidós años de lucha armada, doce de guerra civil, alrededor de un millón de muertos y un millón y medio de desplazados, por fin el gobierno y los militares accedieron a dialogar y negociar, hasta culminar en la firma de los acuerdos de Chapultepec, en México, suscritos por el gobierno de El Salvador, las Fuerzas Armadas y el FMLN. 
Es importante destacar que, en el caso de El Salvador, la guerrilla no derrotó militarmente a las Fuerzas Armadas. Por lo tanto, en estas circunstancias el valor que se le atribuyó al proceso de democratización no se cimentaba en el hecho de haber eliminado a la fuente de violación de los derechos humanos.

La implicación de las Naciones Unidas en el proceso de paz salvadoreño tuvo una gran importancia. Su acordada mediación puso en marcha diferentes mecanismos institucionales por los que se permitió que una Comisión empezara a investigar sobre los abusos cometidos contra los derechos humanos.

La creación de ONUSAL (Misión de Observadores de las Naciones Unidas en El Salvador), como consecuencia de los acuerdos de Ginebra fue decisiva para la supervisión del éxito del cese del fuego, para la desmilitarización del FMLN y la reforma y reducción del ejército salvadoreño, así como para la formación y capacitación de una nueva policia nacional civil. Esta presencia fue, asimismo, eficaz de cara a las elecciones de 1994, en que se daban cita, por primera vez, los comicios presidenciales, legislativos, municipales y en los que participaba por primera vez la izquierda salvadoreña.

Años después de la firma de los Acuerdos de Paz, el Comité de Derechos Humanos, Sociales y Culturales de Naciones Unidas examinó la situación de El Salvador. Después de haber estudiado el informe entregado por el Gobierno de El Salvador y haberse entrevistado con la delegación gubernamental del país, el Comité de Naciones Unidas expresó su profunda preocupación por el alto índice de pobreza de la mayoria de los habitantes de El Salvador y que, en su opinión, no era posible justificar en un pais que habia experimentado un crecimiento económico constante. El Comité recomendó al gobierno enfrentar el problema de la distribución de la riqueza. A su vez, manifestó la lentitud con la cual se estaban implementando ciertas partes de los Acuerdos de Paz, incluyendo las referidas a derechos sociales, culturales y económicos de la población.

Por otra parte, el grupo de trabajo sobre desapariciones forzadas de dicho Comité de Derechos Humanos, se ha preocupado de forma concreta por el tema de los niños desaparecidos, haciendo, a su vez, las pertinentes recomendaciones al gobierno salvadoreño para esclarecer el paradero de los niños desaparecidos.

La presencia de los organismos internacionales es vista como otra oportunidad política, puesto que, además de la presión ejercida al gobierno para encontrar a los niños desaparecidos, no se han mantenido al margen del proceso de creación de la Comisión Nacional de Búsqueda, sino que han participado como un actor más a tener en cuenta y, en términos de Tarrow, podriamos denominarlos aliados. Tal es asi, que en las diferentes comisiones parlamentarias celebradas, han estado presentes representantes de UNICEF y del Alto Comisionado de las Naciones Unidas, facilitando tanto su apoyo a Pro Búsqueda, como prestando asistencia jurídica y técnica para la elaboración del Anteproyecto de Ley presentado a la Asamblea Legislativa. 


\section{Conclusión}

En este artículo se ha ofrecido un análisis introductorio de las oportunidades políticas utilizadas para presionar en la conformación de determinadas políticas públicas por parte de determinados actores, tales como las ONG. Para ello, se ha utilizado como base teórica la teoria de oportunidades políticas desarrollada por Sidney Tarrow, quien define ese concepto las dimensiones congruentes del entomo político que ofrecen incentivos para que los ciudadanos participen en acciones colectivas al afectar a sus propias expectativas de éxito o fracaso.

En este sentido, y tomando como objeto de análisis la acción desarrollada por la ONG Pro Búsqueda de Niños Desaparecidos, se han tratado de detectar una serie de oportunidades políticas existentes en el contexto político salvadoreño, las cuales han sido determinantes para que Pro Búsqueda haya decidido plantear la creación de una Comisión Nacional de Búsqueda de niños desaparecidos a la Asamblea Legislativa.

Se han identificado las siguientes tres grandes oportunidades:

\section{- Inicio de un periodo de estabilidad de la democracia}

Dentro de esta oportunidad, se han destacado dos factores gracias a los cuales se puede hablar de un inicio de la estabilidad de la democracia. Son estos: existencia del principio de alternabilidad y existencia de una cultura política favorable a la democracia, que se traduce en una confianza en el futuro de la democracia como sistema político mejor por parte de la mayoría de los salvadoreño.

\section{-Equilibrio de poderes en la Asamblea Legislativa}

El FMLN, partido que apoya las demandas de Pro Búsqueda en la Asamblea Legislativa, actualmente es el partido que mayor número de representantes tiene en la Asamblea. Esta situación, junto con el hecho de que algunos de los miembros del FMLN están directamente afectados por la desaparición de niños, hace que Pro Búsqueda tenga un apoyo consolidado en la Asamblea.

\section{- Presión de los organismos internacionales en favor de las demandas de Pro Búsqueda}

Naciones Unidas ha estado presente y ha velado por la ejecución de los Acuerdos de Paz, entre los que se recogía la reparación de las violaciones de los derechos humanos cometidas. Por otra parte, este organismo ha prestado asistencia jurídica para la elaboración del Anteproyecto de Ley presentado por Pro Búsqueda. Incluso, representantes de UNICEF y del Alto Comisionado de las 
Naciones Unidas han estado presentes en las diferentes comisiones parlamentarias en las que se ha debatido acerca del Anteproyecto citado, y lo han apoyado.

El Anteproyecto de Ley para la creación de la Comisión Nacional de Búsqueda aun no se ha aprobado. Por ello, este artículo queda abierto a la observación de los resultados obtenidos por Pro Búsqueda como respuesta a las demandas planteadas. He de destacar las dificultades existentes en la consecución de los objetivos de Pro Búsqueda en la Asamblea y que se han puesto de manifiesto a lo largo del trabajo. La cercanía en el tiempo del conflicto armado y la presencia en él (como miembros activos) de muchos de los diputados que actualmente desarrollan su trabajo en la Asamblea Legislativa es un gran obstáculo para que se satisfaga de forma rápida la demanda de crear una Comisión Nacional de Búsqueda.

En este sentido, se mezclan, además de los normales intereses partidistas relacionados con prioridades hacia la aprobación de unas leyes u otras, cuestiones personales que tienen que ver con implicaciones directas con la desaparición de niños durante el conflicto armado y que, de no existir la Comisión de Búsqueda, nunca se sabrian. Por este motivo, el tema se presenta muy delicado y, en mi opinión, sólo se resolverá en la medida en que las implicaciones personales dejan paso a las puramente relacionadas con la resolución de la violación de derechos humanos. Desde mi punto de vista, las demandas de Pro Búsqueda cuentan con el apoyo, tanto de la sociedad salvadoreña como de su clase política. Considero que es una cuestión de tiempo. En el momento en que se dé paso a una nueva generación de diputados que, por cuestiones de edad, no participaron directamente en el conflicto armado, los obstáculos para la creación de la Comisión Nacional de Búsqueda estarán salvados.

\section{Bibliografía}

Alcántara Sáez, Manuel (1999): Sistemas politicos de América Latina. Volumen II. Tecnos.

Atzioni, Amatai (1973): "The third sector and domestic missions", en Public Administration Review, pp. 314-323.

Calderón, Ana Sofia y Marti, Salvador (1998): América Central: Las democracias inciertas. Tecnos.

Casey, John (Tesis doctoral): Non-Government Organizations as Policy Actor: The case of inmigration policies in Spain.

Dalton, Roque (1989): El Salvador. Monografia.UCA Editores

Instituto Interamericano de Derechos Humanos (1999): Memoria del primer curso interamericano de sociedad civil y derechos humanos. UCA Editores. 
Jones, Charles O. (1984): An Introduction to the Study of Public Policy. $3^{\text {a }}$ edición. Brooks/Cole Publishing.

Martínez Peñate, Óscar (1992): El Salvador: Democracia y autoritarismo. Nuevo Enfoque.

McAdam, D; McCarthy, J.D.; Zald, Mayer N. (1996): Movimientos sociales: perspectivas comparadas. ITSMO.

Programa de Naciones Unidas para el Desarrollo (2001): Informe sobre desarrollo humano de El Salvador.

(1992): Directorio de instituciones privadas de desarrollo en El Salvador.

Ramos Rollón, Marisa. "Estructura de oportunidades politicas", en Reyes, Román (dir.): Diccionario critico de Ciencias Sociales. Terminología cientificosocial. Aproximación critica. Universidad Complutense de Madrid.

Subirats, Joan y Gomá, Ricard (1993): "La elaboración pluralista de las politicas locales: El papel de las ONG", en Revista d'Investigació i Assesorament. Patronat Flor de Maig, Diputació de Barcelona, $N^{\circ} 12$, Barcelona.

Tarrow, Sidney (1994): El poder en movimiento. Los movimientos sociales, la acción colectiva y la politica. Alianza Universidad.

Torres Rivas, Edelberto: "La sociedad civil en la construcción democrática" (En Internet, página del Instituto Internacional de Gobernabilidad: http:// www.iigov.org)

Urcuyo, Constantino (1997): Partidos politicos y gobernabilidad en América Latina. PNUD.

\section{Notas}

1. Ramos Rollón, Marisa. "Estructura de oportunidades politicas", en Reyes, Román (Dir.): Diccionario critico de Ciencias Sociales. Terminologia cientifico-social. Aproximación critica. Universidad Complutense de Madrid.

2. McAdam, D.; McCarthy, J.; Zald, Mayer N. (1996): Movimientos sociales: perspectivas comparadas. ITSMO.

3. Tarrow, Sidney (1994): El poder en movimiento. Los movimientos sociales, la acción colectiva y la politica. Alianza Universidad.

4. Alcántara Sáez, Manuel (1999). Sistemas politicos de América Latina. Volumen II. Tecnos.

5. Programa de Naciones Unidas para El Salvador (2001): Informe sobre desarrollo humano de El Salvador.

6. Martinez Peñate, Óscar (1992): El Salvador: Democracia y autoritarismo. Nucvo enfoque. 
7. Urcuyo, Constantino (1997). Partidos politicos y gobernabilidad en América Latina. PNUD.

8. Subirats, Joan y Gomá, Ricard (1993), “La elaboración pluralista de las politicas locales: el papel de las ONG", en Revista d'Investigació $i$ Assesorament. Patronat Flor de Maig, Diputació de Barcelona, $\mathrm{n}^{\circ} 12$, Barcelona.

9. Martínez Peñate, Op. cit.

10. Tomado de uno de los documentos anexos al anteproyecto de ley presentado a la Asamblea, el cual fue facilitado por Jon Cortina, presidente de la ONG.

11. Artículo 3 del Anteproyecto.

12. Las reformas que se llevaron a cabo se pueden agrupar en tres órdenes:

- Transformaciones tendentes a la desmilitarización de la vida política y de la sociedad.

- Reformas en el sistema de justicia.

- Transformaciones en el sistema político electoral.

13. Programa de Naciones Unidas para el Desarrollo (2001): Informe sobre desarrollo humano de El Salvador.

14. Ídem.

15. Alcántara Sáez, Manuel (1999): Sistemas políticos de América Latina. Volumen II. Tecnos. 